\title{
Ruscus Genus: A Rich Source of Bioactive Steroidal Saponins
}

Authors

Affiliation
Milena Masullo, Cosimo Pizza, Sonia Piacente

Dipartimento di Farmacia, Università degli Studi di Salerno, Fisciano (SA), Italy
Key words

- Ruscus genus

- Asparagaceae

- spirostanol saponins

- furostanol saponins

chronic venous insufficiency

\section{Abstract \\ $\nabla$}

The genus Ruscus (Asparagaceae family) is native to the Mediterranean, Southern and Western Europe and is represented by perennial, rhizomatous, and evergreen shrubs. Among the approximately seven species spread throughout Europe up to Iran, Ruscus aculeatus L. (butcher's broom) is the most widely distributed and appreciated. This review provides an overview of the traditional use of Ruscus spp., the current knowledge of the chemistry of this genus, and the pharmacological studies carried out on Ruscus spp. extracts. The underground parts of Ruscus plants are a source of steroidal saponins that can be classified into two structural classes: the hexacyclic spiro-

\section{Botany of Ruscus Genus}

$\nabla$

The genus Ruscus has shuttled between various families including Ruscaceae [1], Convallariaceae, and Liliaceae, but currently, in the APG III classification system, it has been included in the Asparagaceae family [2]. The genus is native to the Mediterranean, Southern and Western Europe [3]. The species are represented by perennial, rhizomatous, and evergreen shrubs with multiple stems arising from a creeping, thick, sympodially branched rhizome to form an oval, pyramidal bush. Stems appear striate, green, erect, and much branched, growing to $1 \mathrm{~m}$ tall. Leaves are reduced to triangular scarious scales up to $5 \mathrm{~mm}$ long and replaced functionally by rigid cladodes (flattened, leaf-like stem tissue also known as asphylloclades) $2-18 \mathrm{~cm}$ long and $1-8 \mathrm{~cm}$ broad, each arising from a leaf axil; cladodes are ovate, entire, dark green, and spine-pointed. Flowers are small, arising from the axil of a small scarious bract in the center of the upper surface of a cladode, each with a short pedicle. Perianth is greenish-white, approximately $3 \mathrm{~mm}$ long, and made stanol saponins and the pentacyclic furostanol saponins. The main aglycones are ruscogenin and neoruscogenin. From the pharmacological point of view, the most studied Ruscus species is undoubtedly $R$. aculeatus, a very ancient phlebotherapeutic agent. Pharmacological investigations since the discovery of the vasoconstrictive and venotonic properties of ruscogenin and neoruscogenin in the underground parts of $R$. aculeatus are discussed. Preparations based on Ruscus species are currently used for the treatment of chronic venous insufficiency, varicose veins, haemorrhoids, and orthostatic hypotension. Finally, analytical techniques for the quality control of $R$. aculeatus extracts are reported.

up of two whorls of three segments bearing papillae. Some species are monoecious while others are dioecious. In the latter, male and female plants are very similar in appearance; female flowers show a cup formed from fused stamen filaments around the superior, unilocular ovary, which has a subsessile capitate stigma, while male flowers possess three stamens and green or violet filaments fused into a tube around an undeveloped ovary. Fruits are bright red globose berries of 8 $14 \mathrm{~mm}$ in diameter with 1-4 large seeds [2]. The genus includes approximately seven species spread throughout Europe up to Iran (Yeo 1968) including Ruscus aculeatus L., Ruscus colchicus Yeo, Ruscus hypoglossum L., Ruscus hypophyllum L., Ruscus hyrcanus Woronow, Ruscus x microglossus Bertol., and Ruscus streptophyllus Yeo.

$R$. aculeatus is known with the common English name "butcher's broom". Jekyll described the derivation of its name as "In country places where it abounds, butchers use the twigs tied in bunches to brush the little chips of meat off their great chopping-blocks, that are made of solid sections of elm trees, standing three and half feet high 
and about two and half feet across" ( $\bullet$ Fig. 1). The common Italian name pungitopo and the German Mausedorn signify "mousestinger" and are related with the old practice to put the wellarmed branches around stored food to protect it from pests [4]. The plant has also a nutritional use in the Mediterranean countries, where the young shoots are eaten like asparagus spears [5], and the seeds were once used to make a coffee substitute. $R$. aculeatus is the most widely distributed Ruscus species, while $R$. hypoglossum, R. hypophyllum and $R$. x microglossus are representatives of the Mediterranean area. $R$. streptophyllus, a rare species, is endemic of Maidera, and $R$. colchicus and $R$. hyrcanus are endemic of Caucasus and Azerbaijan, respectively [4].

$R$. hypophyllum presents the greater morphological variation within the genus. Its distribution range is throughout the western Mediterranean region, principally Northern Africa as far east as Tunisia. $R$. hypoglossum represents a gentler version of $R$. aculeatus for the presence of larger and softer cladodes. It can be distinguished by its large foliaceous inflorescence bracts. Its Italian common name bislingua, meaning "double-tongue", is due to one tongue being the bract and the other the cladode. $R$. $x$ microglossus is probably a hybrid between $R$. hypoglossum and $R$. hypophyllum [4].

Ruscus ponticus Woronow is a synonym of R. aculeatus L. and is widespread in Crimea and Caucasus, particularly in the forests of West and East Georgia [6]. R. ponticus is well known in this country for the preparation of ruscoponin, obtained from the underground parts of the plant [6].

\section{Traditional Medicine}

$\nabla$

Although the aerial parts of Ruscus species are edible, the rhizomes and roots of the plants are used in traditional medicine as phytotherapeutic products. During the Middle Ages, the young shoots of $R$. aculeatus were not only used as food, but also as a medicinal agent for the treatment of heavy legs, urinary disorders, and abdominal pain [7]. The hydroalcoholic extract of $R$. aculeatus rhizomes is traditionally used as a vascular preventive and tonic in preparations for disorders involving the venous system, including venous fragility and varicose veins $[8,9]$. The underground parts of $R$. aculeatus have been also used as diuretic and anti-inflammatory agents, as well as for the treatment of hemorroids and atherosclerosis. As a remedy for diseases of the circulatory system, $R$. aculeatus has a long tradition of proven success in Europe. A written record of its use as a phlebotherapeutic agent dates back at least 2000 years. In the middle of the 20th century, the main active substances, the steroidal sapogenins ruscogenin and neoruscogenin, were identified [7]. Indeed, $R$. aculeatus preparations are widely distributed in Europe, and have been used for more than 40 years to treat chronic venous insufficiency and vasculitis $[10,11]$.

In European tradition, both the aerial parts (leaves) and the rhizome of $R$. aculeatus are considered to be diuretic and mildly laxative [12]. In the same way, in the folk medicine of Turkey, a decoction of the roots of $R$. aculeatus is widely used internally as a diuretic and for the treatment of urinary system disorders, such as nephritis, and towards eczema as well as kidney stones [13]. In Palestinian folk medicine, the rhizome extract is used externally against skin diseases [14], while in central Italy it is used in the treatment of warts and chilblains [15]. In some parts of Italy the same preparation is used for colitis and diarrhea [16]. It is also used locally against inflammation and arthritis [16].

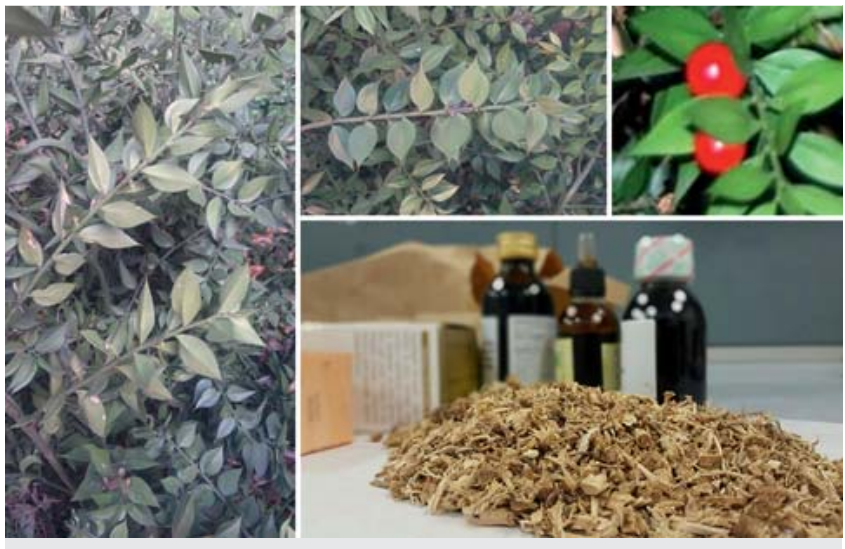

Fig. 1 R. aculeatus L. (Color figure available online only.)

Not only rhizomes but also other parts of the plants have been used in traditional medicines. Indeed, the aerial parts of $R$. aculeatus are traditionally used as diuretics, mostly in Mediterranean and Middle East countries [16]. In Turkey, the decoction of berries of $R$. hypoglossum is applied externally for boils and warts, while its fresh leaves are used for livestock against cold and mastitis [16]. The leaves of $R$. colchicus are used by the local population for feeding livestock in order to yield more milk and to increase its fat content [17].

In Iran, $R$. hyrcanus is traditionally used as a diuretic, appetizer, antilaxative, vasoconstrictor, antibleeding, antinephritis, anti-infection, aperient, antivaricose, and laxative remedy [18].

\section{Chemistry \\ $\checkmark$}

The underground parts of Ruscus plants are a source of steroidal saponins. Steroidal saponins consist of a C27 skeleton, typically an oxidized cholesterol derivative, bearing varying numbers of sugar residues at different positions. The steroidal saponins isolated from Ruscus genus can be classified into two structural classes, both of them bearing a sugar chain linked mostly to C-1: the hexacyclic spirostanol saponins, which possess a bicyclic ketal at C-22 and the pentacyclic furostanol saponins, which usually contain a hemiketal function at $\mathrm{C}-22$, and a glycosidic linkage (typically to a single $\beta$-D-glucose residue) at C-26 [19].

The diol aglycones (25R)-spirost-5-en- $1 \beta, 3 \beta$-diol, named ruscogenin (1), and spirost-5,25(27)-dien- $1 \beta, 3 \beta$-diol, named neoruscogenin (2), were first isolated from the subterranean parts of $R$. aculeatus and described in 1955-1957 [20]. These aglycones and derived spiro- and furostanol glycosides were subsequently also isolated from other species of the genus.

Moreover, a series of cholestane glycosides have been isolated only from $R$. colchicus, $R$. hypoglossum, and $R$. hypophyllum [2123 ], and few examples of pregnane glycosides have been reported in $R$. aculeatus, $R$. hypoglossum, and $R$. ponticus [6,24]. Generally, the fresh underground parts of the plant material were extracted with methanol, and sometimes the obtained crude extract was partitioned between water and $n$-butanol. The fractionation of the selected extract was performed by a combination of column chromatographic methods over a porous polymer resin (Diaion HP-20), silica gel and octadecylsilanized (ODS) silica gel, Sephadex LH-20, or by droplet countercurrent chromatography (DCCC) as well as HPLC. 
The first characterization of the structures of deglucoruscoside and ruscoside was obtained in 1971 by acid and enzymatic hydrolysis and degradation studies. Successively, the structure elucidation of steroidal saponins isolated from the Ruscus genus was obtained by spectroscopic methods including $1 \mathrm{D}-\left({ }^{1} \mathrm{H},{ }^{13} \mathrm{C}\right.$ and TOCSY) and 2D-NMR (DQF-COSY, HSQC, HMQC, HMBC, NOESY and ROESY) experiments as well as ESIMS and HRMS analyses. Acid hydrolysis of saponins was carried out to afford the sugar moieties, which were successively identified by GC-MS.

\section{Spirostanol saponins from Ruscus spp.}

The spirostanol saponins contain ruscogenin (1) and neoruscogenin (2) as aglycones ( $\mathbf{F i g}$. 2). The structure of ruscogenin was compared with that of the typical plant sapogenin (25R)-spirost5 -en-3 $\beta$-ol, also known as diosgenin [25], revealing that it differed from that of diosgenin only for the occurrence of a $\beta$-hydroxy group at $\mathrm{C}-1$, being identical for all other structural features, including orientation of the $\mathrm{C}-3$ oxygen atom ( $3 \beta$-equatorial) and ring junctions (B/C trans, C/D trans, D/E cis) [25]. Three saponins named ruscin (also known as ruscoponticosides D) (3), desglucoruscin (also known as ruscoponticosides C) (4), and desglucodesrhamnoruscin (5), containing neoruscogenin as the aglycone, have been firstly described in 1971 from $R$. aculeatus [26]. These compounds, described among the main constituents, are accompanied by the corresponding (25R)-25,27-dihydro derivatives, of which the respective structures are 6,7 , and 8 ( Fig. 2). Like all of the spirostanol prosapogenins, all of these take origin from furostanol saponins carrying a glucose residue at C-26.

Since 1971, from the underground parts of $R$. aculeatus, several spirostane derivatives have been isolated (9-28) (O Fig. 3) [25, 27-32]. All isolated neoruscogenin derivatives are characterized by the presence of a sugar chain only at C-1. Among these, compounds 9-19 possess an $\alpha$-L-rhamopyranosyl-( $1 \rightarrow 2)$ - $\alpha$-L-arabinopyranosyl sugar chain at $\mathrm{C}-1$. Substitution with acetyl groups, sulphate ions, and 2-hydroxy-3-methylpentanoyl moieties are present on the sugar units. Hydroxylation at positions 23 and 24 of the spiro system (15-19) $[29,32]$ and also the presence of a glucopyranosyl unit at C-23 (15-16) can occur [29].

Aculeoside A (17) represents an unusual bisdesmosidic spirostanol saponin, having 6-deoxy-D-glycero-L-threo-4-hexosulose linked to the C-24 hydroxyl group of the aglycone. Aculeoside A was active as a cyclic AMP phosphodiesterase inhibitor [30]. Other unusual structures are spilacleosides $A$ and $B$ (18 and 19) having spiro 1,3-dioxolan-4-one structures, made up of aculeoside $A$ and (2R,3S)-2,3-dihydroxy-3-methylpentanoic acid [32]. These were reported as rare examples of natural compounds containing a spiro structure with unusual features: they are the first examples where both segments intramolecularly construct a 1,3-dioxolan-4-one ring with a spiro system at C-2 and where the naturally derived 2,3-dihydroxy-3-methylpentanoic acid has the opposite configuration at $\mathrm{C}-3$ with respect to the same acid produced by a mutant strain of Neurospora crassa and by Heliotropium strigosum showing a $(2 R, 3 R)$ configuration [32]. Few natural products intramolecularly incorporating a spiro 1,3-dioxolan-4-one ring are known and the usefulness of this moiety as a building block in asymmetric organic synthesis has been often reported [32]. The structural peculiarities of aculeoside B (20) are the presence of three acetyl esters at the inner galactose unit and the glucosyloxy group attached to C-23 of the aglycone [31]. Other examples of ruscogenin derivatives isolated from the underground parts of $R$. aculeatus are represented by a saponin

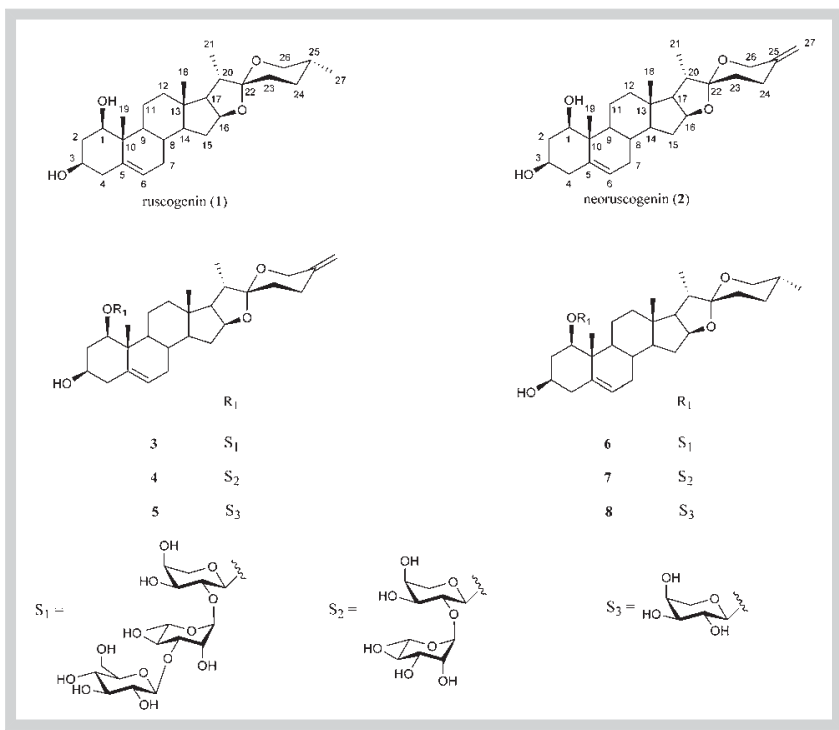

Fig. 2 The aglycones ruscogenin (1) and neoruscogenin (2) and their derived saponins (3-8).

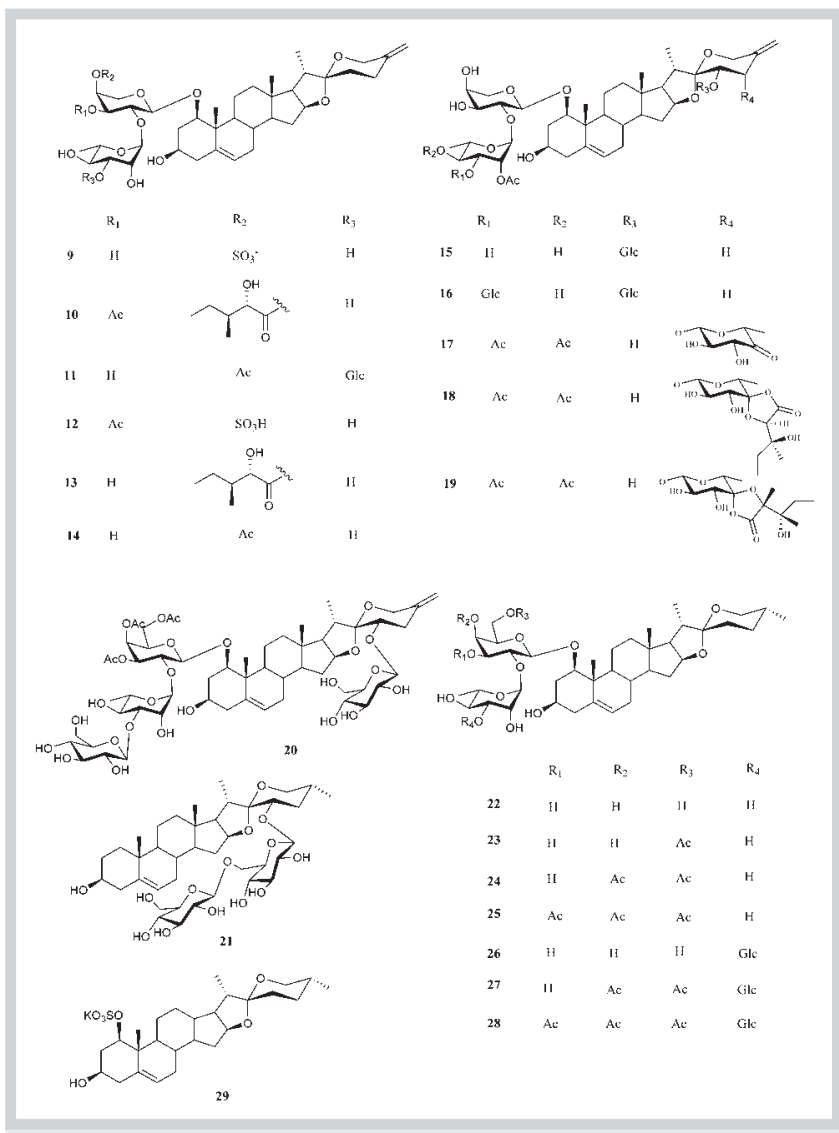

Fig. 3 Spirostanol saponins isolated from $R$. aculeatus.

having a diglycoside moiety at C-23 of the aglycone (21) [25] and by a series of ruscogenin glycosides characterized by a diglycoside moiety made up of rhamnose and galactose units linked to $\mathrm{C}-1$, with the presence of an additional glucose unit or acetyl groups on the sugar chain (22-28) [33]. A sulphated derivative 
at C-1 of ruscogenin (29) has been isolated from $R$. aculeatus rhizomes [34].

From the rhizomes of $R$. colchicus and $R$. hypoglossum, the two sapogenins $\mathbf{1}$ and $\mathbf{2}$ along with the spirostane saponins 3-8 were isolated [19].

An HPLC-ESIMS ${ }^{n}$ method, based on high-performance liquid chromatography coupled to electrospray positive ionization multistage ion trap mass spectrometry, has been used as an effective tool to rapidly identify and guide the isolation of saponins from the leaves of $R$. colchicus, among which there are four spirostanol derivatives (30-33) [17] ( Fig. 4).

From the cladophylls of $R$. hypoglossum, four neoruscogenin derivatives (34-37) have been isolated [35] ( $\odot$ Fig. 4). Another six compounds (38-43), some of which characterized by the presence of a primary alchoholic function at C-27 (41-42), and 44 have been isolated from the roots and rhizomes of $R$. hypoglossum (॰ Fig. 4) [21,36].

The first phytochemical investigation on the rhizomes of $R$. hypophyllum was performed in 1971 with the isolation and identification of diosgenin and the two isomers (25R and 25S) of ruscogenin [36]. In the last years ruscoponticoside C (4), two spirostanol derivatives (22-23) [22], and five spirostanol derivatives $\{(45-47)[22]$ and $(48,49)[23]\}$ have been detected in the rhizomes of $R$. hypophyllum ( $\bullet$ Fig. 5).

A phytochemical investigation of the roots of $R$. ponticus led to the isolation of diosgenin and neoruscogenin (1) [37], along with ruscoponticosides C (4) and D (3) [38].

The ${ }^{13} \mathrm{C}$ NMR data of the aglycone moieties of spirostanol derivatives $3, \mathbf{1 5}, \mathbf{2 1}, \mathbf{2 2}, \mathbf{2 9}, \mathbf{3 0}$, and 45-47 are reported in $\odot$ Table 1.

\section{Furostanol saponins from Ruscus spp.}

Pentacyclic furostanol saponins can be divided into those that possess either a hydroxy or methoxy moiety at C-22 and those that possess a $\Delta 20(22)$-unsaturation. Two furostanol saponins, containing a double bond in the $\mathrm{C} 25-\mathrm{C} 27$ position, have been described in $R$. aculeatus, desglucoruscoside (also known as ruscoponticoside E) (50), and ruscoside (51). The corresponding (25R)25,27-dihydro derivatives ( 52 and $\mathbf{5 3}$ ) are also present as minor constituents [19].

From the underground parts of $R$. aculeatus, several furostane derivatives have been isolated (54-62) [39], (63-70) [27], (71-75) [29] ( $\odot$ Figs. 6 and 7). Also, sulphated compounds 76-79 have been identified $[34,40]$. As regards to these compounds, OuladAli et al. reported the isolation of compound 76, which is constitutionally identical to compound 79 [34] ( Fig. 7). The stereochemistry at C-22 was left unassigned, but comparison between the ${ }^{13} \mathrm{C}$-NMR data of the two compounds evidenced some small but not insignificant differences, pointing to a stereoisomeric relationship [40]. Moreover, De Marino et al. described the isolation of a furostanol saponin with a double bound between C20-C22 (80), reported for the first time in the underground parts of R. ponticus [40] ( Fig. 7).

Rhizomes of $R$. colchicus and $R$. hypoglossum were found to contain the furostanol saponins 50-53, along with compound 81 [19] (๑ Fig. 8).

From the leaves of $R$. colchicus, ruscoponticoside E (50) and ceparoside B (52) along with compounds 82-96 [17] were identified (๑ Fig. 8).

Furostanol compounds 50, 51, 54, 63, 80, and 97-98 were isolated from $R$. ponticus underground parts, and compounds 99107 from $R$. ponticus leaves [6] (๑ Fig. 9).

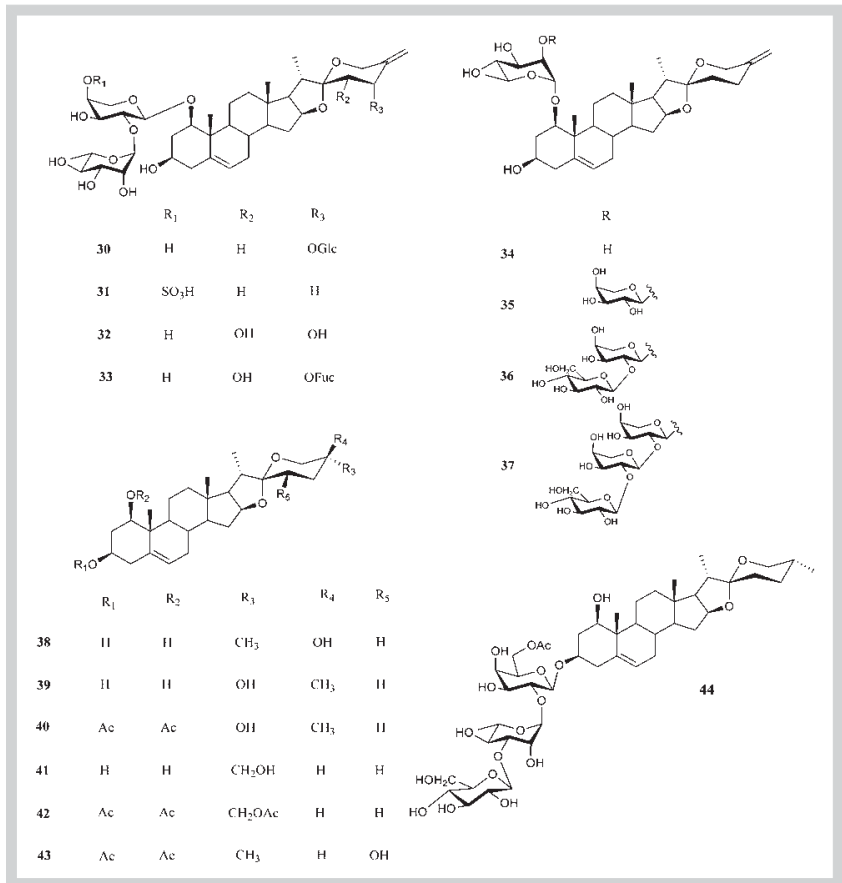

Fig. 4 Spirostanol saponins isolated from $R$. hypoglossum (30-44).

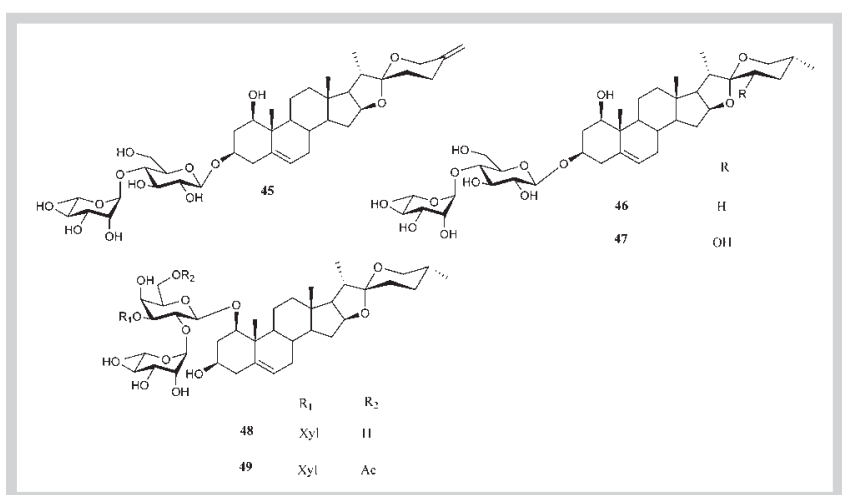

Fig. 5 Spirostanol saponins isolated from R. hypophyllum (45-49).

The ${ }^{13} \mathrm{C}$ NMR data of the aglycone moieties of furostanol deriva-

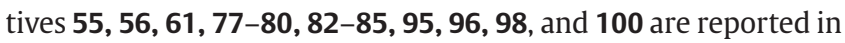
- Table 2.

Stereochemistry of furostanol and spirostanol saponins In both furostanol and spirostanol saponins, C-25 is found naturally with either the $R$ or $S$ configuration. Further structural diversity is generated in this class of natural products by differences in the stereochemistry of C- 22 and in the cis or trans fusion of the steroid A and B rings as well as differences in the steroid hydroxylation and glycosylation patterns. This structural variation may account for the wide range of bioactivities reported for steroidal saponins [41].

By NMR spectroscopy, the stereochemistry of C-25 in spirostanol saponins may be determined thanks to the proton vicinal coupling constants between $\mathrm{H}-24$ and $\mathrm{H}-26$ as well as by comparison of the ${ }^{1} \mathrm{H}$ and ${ }^{13} \mathrm{C}$ NMR chemical shifts of the steroid $\mathrm{F}$ ring with literature values [42-44]. Infrared spectroscopy has been used for 
Table $1{ }^{13} \mathrm{C}$ NMR data of the aglycone moieties of spirostanol derivatives $\mathbf{3}, \mathbf{1 5}, \mathbf{2 1}, \mathbf{2 2}, \mathbf{2 9}, \mathbf{3 0}$, and 45-47.

\begin{tabular}{|c|c|c|c|c|c|c|c|c|c|c|}
\hline & $3^{\mathrm{a}}[27]$ & $15^{b}$ [29] & $21^{\mathrm{a}}$ [25] & $22^{\mathrm{a}}[33]$ & $29^{a}[34]$ & $30^{c}[17]$ & $32^{\mathrm{a}}$ [79] & $45^{\mathrm{a}}[22]$ & $46^{\mathrm{a}}[80]$ & $47^{\mathrm{a}}[22]$ \\
\hline 1 & 84.8 & 84.5 & 37.8 & 84.2 & 84.1 & 84.6 & 83.8 & 77.6 & 37.3 & 37.4 \\
\hline 2 & 38.1 & 37.4 & 32.6 & 38.0 & 39.8 & 37.1 & 37.3 & 40.8 & 30.0 & 30.2 \\
\hline 3 & 68.2 & 68.2 & 71.2 & 68.1 & 68.0 & 69.1 & 68.1 & 74.9 & 78.2 & 78.8 \\
\hline 4 & 43.8 & 43.9 & 43.5 & 43.8 & 40.1 & 43.3 & 43.6 & 39.6 & 39.1 & 39.3 \\
\hline 5 & 139.6 & 139.5 & 141.9 & 139.5 & 139.0 & 139.8 & 139.3 & 139.0 & 140.7 & 140.8 \\
\hline 6 & 124.8 & 124.7 & 121.1 & 124.7 & 125.2 & 126.0 & 124.6 & 125.0 & 121.6 & 121.8 \\
\hline 7 & 32.0 & 32.2 & 32.4 & 31.9 & 33.0 & 32.5 & 31.8 & 32.1 & 32.0 & 32.2 \\
\hline 8 & 33.1 & 33.0 & 31.6 & 33.0 & 31.9 & 33.8 & 32.8 & 32.7 & 31.5 & 31.6 \\
\hline 9 & 50.5 & 50.4 & 50.4 & 50.5 & 49.8 & 51.4 & 50.3 & 51.0 & 50.1 & 50.2 \\
\hline 10 & 43.0 & 42.9 & 37.0 & 42.8 & 43.7 & 43.5 & 42.7 & 43.5 & 36.9 & 37.0 \\
\hline 11 & 23.9 & 23.9 & 21.2 & 24.0 & 23.6 & 24.6 & 23.9 & 24.0 & 21.0 & 21.1 \\
\hline 12 & 40.3 & 40.7 & 40.4 & 40.4 & 41.9 & 41.2 & 40.4 & 40.3 & 40.0 & 39.9 \\
\hline 13 & 40.2 & 40.8 & 41.0 & 40.1 & 40.6 & 41.5 & 40.5 & 40.1 & 40.9 & 40.5 \\
\hline 14 & 56.9 & 56.8 & 56.7 & 57.1 & 56.7 & 57.9 & 56.7 & 56.7 & 56.5 & 56.6 \\
\hline 15 & 32.4 & 32.1 & 32.0 & 32.4 & 32.8 & 32.5 & 32.1 & 32.2 & 32.1 & 31.8 \\
\hline 16 & 81.5 & 81.8 & 81.3 & 81.1 & 81.1 & 83.0 & 83.1 & 81.3 & 81.5 & 81.1 \\
\hline 17 & 63.0 & 62.3 & 62.1 & 62.9 & 63.1 & 63.0 & 61.2 & 63.0 & 62.3 & 62.9 \\
\hline 18 & 16.7 & 17.3 & 17.3 & 16.8 & 16.6 & 16.6 & 16.7 & 16.4 & 16.4 & 16.4 \\
\hline 19 & 15.1 & 15.0 & 19.5 & 15.0 & 14.8 & 15.1 & 14.9 & 13.6 & 19.2 & 19.4 \\
\hline 20 & 41.8 & 35.7 & 35.7 & 41.9 & 43.1 & 37.0 & 36.9 & 41.7 & 35.6 & 42.0 \\
\hline 21 & 15.0 & 14.6 & 14.7 & 14.9 & 15.0 & 14.1 & 14.5 & 14.9 & 14.6 & 15.0 \\
\hline 22 & 109.5 & 110.7 & 110.8 & 109.2 & 109.2 & 113.8 & 112.5 & 109.3 & 111.6 & 109.3 \\
\hline 23 & 33.2 & 77.2 & 76.2 & 31.7 & 31.9 & 32.5 & 69.5 & 33.1 & 67.3 & 31.8 \\
\hline 24 & 29.0 & 37.7 & 37.6 & 29.2 & 29.2 & 73.2 & 74.0 & 28.8 & 38.6 & 29.3 \\
\hline 25 & 144.5 & 143.9 & 31.4 & 30.6 & 30.7 & 147.0 & 146.1 & 144.3 & 31.4 & 30.6 \\
\hline 26 & 65.0 & 64.1 & 65.8 & 66.8 & 66.8 & 64.3 & 60.6 & 64.9 & 65.8 & 66.9 \\
\hline 27 & 108.6 & 109.8 & 16.8 & 17.2 & 17.3 & 107.8 & 112.4 & 108.6 & 16.8 & 17.3 \\
\hline
\end{tabular}

a Pyridine- $d_{5} ;{ }^{\mathrm{b}}$ pyridine- $d_{5}-\mathrm{CD}_{3} \mathrm{OD}(11: 1) ;{ }^{\mathrm{c}} \mathrm{CD}_{3} \mathrm{OD}$

distinguishing between spirostanol and furostanol saponins, as the former possesses characteristic absorption bands at around $980,920,900$, and $860 \mathrm{~cm}^{-1}$. The relative intensities of the 920 and $900 \mathrm{~cm}^{-1}$ bands are predictive of the C-25 configuration in spirostanols ( $920>900$ in 25S; $900>920$ in 25R) [41,45].

The determination of C-25 stereochemistry is more challenging in furostanol saponins, which do not possess the rigid bicyclic system present in their spirostanol analogues. There are reports in which the intensities of IR absorption bands have been used to assign the C-25 configuration in furostanols [46,47], as well as in spirostanols, but there is no basis for the former application [48, 49]. The most reliable method for determination of the $\mathrm{C}-25$ configuration in furostanol saponins is conversion to the corresponding spirostanol form, either through enzymatic cleavage of the $\mathrm{C}-26$ glucose residue specifically to effect ring closure of the side chain [50] or by complete hydrolysis to yield the free spirostanol aglycone.

In most of the reported furostanol saponins, the absolute configuration of C-25 has been assigned directly by NMR spectroscopy. Empirically, it has been found that both the chemical shifts and resolution of the geminal proton resonances of $\mathrm{H}_{2}-26$ ( $\delta \mathrm{a}$ and $\delta \mathrm{b}, \Delta \mathrm{ab}=\delta \mathrm{b}-\delta \mathrm{a})$ are dependent on the configuration of $\mathrm{C}-25$. The resolution of the $\mathrm{H}_{2}$-26 resonances is normally used to assign C25 stereochemistry, as these signals are more separated in $25 \mathrm{~S}$ ( $\Delta \mathrm{ab} \geq 0.57 \mathrm{ppm}$ ) than $25 R$ furostanols ( $\Delta \mathrm{ab} \leq 0.48 \mathrm{ppm})[48,49]$. In addition, the chemical shift of $\mathrm{H}_{3}-27$ occurs at a slightly higher field in $25 R\left(\delta_{\mathrm{H}} 0.98-1.03 \mathrm{ppm}\right)$ compared with $25 S$ saponins $\left(\delta_{\mathrm{H}}\right.$ $1.01-1.05 \mathrm{ppm})$. The initial reports gave examples in both pyridine- $d_{5}$ and methanol- $d_{4}[48,49]$, and this predictor of C-25 stereochemistry has since been widely applied in both of these solvents [41]. Challinor et al. observed that the chemical shifts of
$\mathrm{H}_{2}-26$ are, in general, more resolved in $25 \mathrm{~S}$ than $25 \mathrm{R}$ compounds, and that this empirical rule in different solvents led to conflicting assignments of stereochemistry. An experimental survey revealed that, while the chemical shifts of $\mathrm{H}_{2}-26$ exhibit a dependence on C-25 configuration, it is less pronounced in methanol$d_{4}$ than in pyridine- $d_{5}$ solvent, and thus the general rule derived for pyridine- $d_{5}$ fails when NMR spectra are acquired in methanol- $d_{4}$. A modified empirical method for the direct assignment of C-25 stereochemistry in furostanol saponins in methanol- $d_{4}$ $(\Delta \mathrm{ab}=0.45-0.48 \mathrm{ppm}$ for $25 \mathrm{~S} ; \Delta \mathrm{ab}=0.33-0.35 \mathrm{ppm}$ for $25 R$ ) has been provided [41]. Therefore, the stereochemistry of C-25 of furostanol saponins isolated before this modified empirical method was deduced could be reversed.

\section{Other steroidal saponins from Ruscus spp.}

Cholestane glycosides have been reported in $R$. hypophyllum, $R$. hypoglossum and $R$. colchicus. The first report was compound 108 in $R$. hypoglossum [21]. The six cholestane saponins 109-113 [22] and 114 have been isolated from $R$. hypophyllum [23]. Moreover, a sulphated cholestane glycoside (115) has been reported in R. colchicus [17] (๑ Fig. 10).

In 1972, two pregnane glycosides (116 and 117) were identified in the rhizomes of $R$. aculeatus [51]. Compound 116 was also isolated from $R$. hypoglossum [24], while more recently compounds 117 and 118 were identified in the underground parts of R. ponticus [6] ( Fig. 10). Compound 118 represents an example of pregnane with the presence of a five-membered lactone ring between C-22 and C-16. These kinds of lactone-type sapogenols and their glycosides might be biosynthetically derived from the genuine 23,26-oxygenated spirostane or furostane type [6]. The 


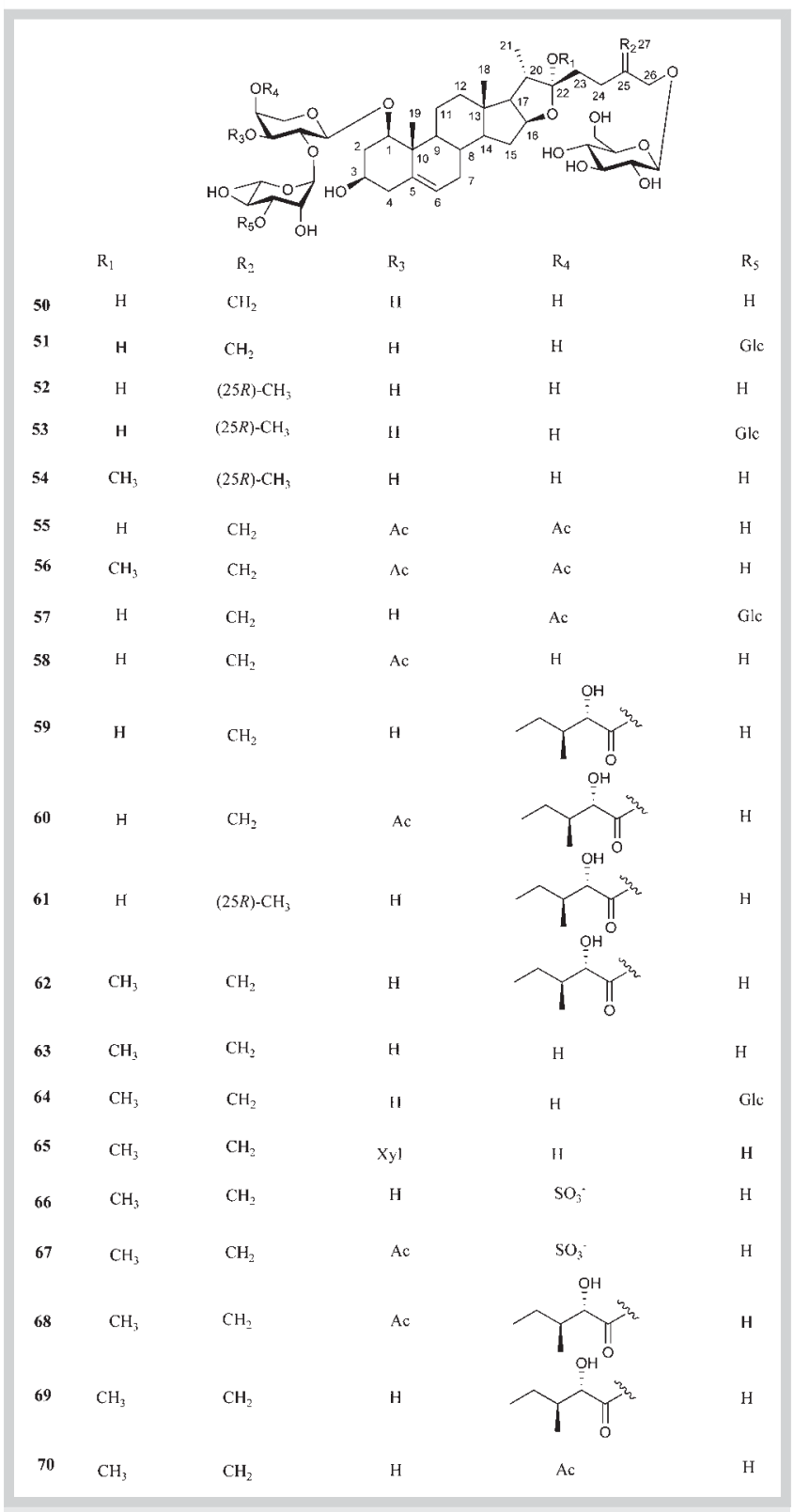

Fig. 6 Furostanol saponins (50-70) isolated from R. aculeatus.

${ }^{13} \mathrm{C}$ NMR data of the aglycone moieties of compounds 109,111 , 112,115 , and 118 are reported in $\odot$ Table 3.

\section{Pharmacological Activity \\ $\nabla$}

From the pharmacological point of view, the most studied Ruscus species is undoubtedly $R$. aculeatus, a very ancient phlebotherapeutic agent. Since the discovery of the vasoconstrictive and venotonic properties of ruscogenin and neoruscogenin, $R$. aculeatus L. was extensively used, especially in Germany and France, for the treatment of chronic venous insufficiency, varicose veins, haemorrhoids, and orthostatic hypotension [7].

In 1972, sapogenins isolated from $R$. aculeatus displayed anti-inflammatory activity on rat paw edema, but were inactive on rat capillary fragility. Vasoconstrictor effects were also observed on the vessels of isolated rabbit ears, but only ruscogenin derivatives

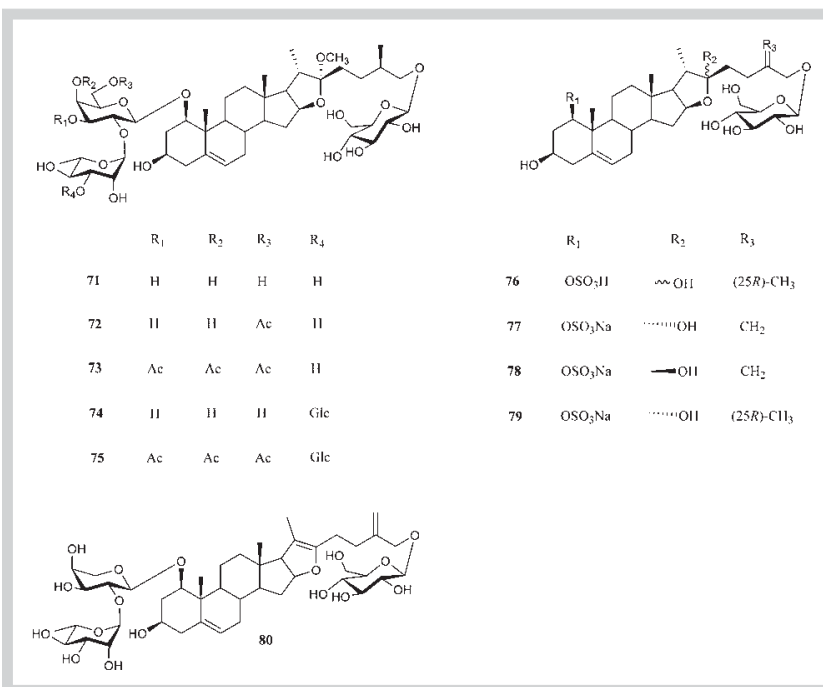

Fig. 7 Furostanol saponins (71-80) isolated from $R$. aculeatus.

significantly decreased capillary permeability in the rabbit. The acute oral and parenteral toxicities were low in mice and rats, and prolonged oral administration of high doses was well tolerated in rats [52].

Rudofsky reported a decrease of about $10 \%$ in venous capacity $2 \mathrm{~h}$ after oral administration of Ruscus hydroalcoholic extract in healthy volunteers. Patients with chronic venous insufficiency treated with Ruscus extract maintained constant venous tone and had improved venous emptying, unlike placebo-treated patients [53].

In isolated cutaneous veins, Ruscus extract caused contractions owing to activation of postjunctional $\alpha-1$ and $\alpha$-2 adrenergic receptors by releasing endogenous norepinephrine (NE) from adrenergic nerve endings and through a direct action on the venous smooth muscle $[54,55]$. The contractions caused by the extract were increased by local warming and reduced by cooling $[9,56]$. Intravenous administration of Ruscus extract ( $5 \mathrm{mg} / \mathrm{kg}$ ) was also tested in the microcirculation in vivo, investigating its effects on the diameter of arterioles and venules of the hamster cheek pouch and the influence of temperature on the observed effects [8]. Moreover, the effects of Ruscus extract and the flavonoid hesperidine methylchalcone were investigated in the hamster cheek pouch on increased microvascular permeability induced by various agents, such as bradykinin, histamine, and leukotriene B4.

A study aimed at evaluating the factors contributing to the efficacy of $R$. aculeatus in the treatment of venous insufficiency showed that ruscogenins were ineffective on hyaluronidase activity, but exhibited remarkable anti-elastase activity [57]. Their anti-edematous effects have also been demonstrated [58]. Another study reported a comparison of the effects of $R$. aculeatus extract and norepinephrine on the contractions in veins. Contractions to norepinephrine were greater in control veins than in varicose tributaries. Contractions to the extract were greater in varicose tributaries than in greater saphenous veins from varicose patients. Contractions to norepinephrine were reduced similarly by $\alpha-1$ and $\alpha$-2-adrenergic agonists in control and varicose veins, but to a greater extent by $\alpha$-2-blockade in greater saphenous veins from varicose patients. Contractions to Ruscus extract were not reduced by $\alpha$-1-adrenergic blockade in control veins, but were reduced by $\alpha$-2-adrenergic blockade in varicose veins. 


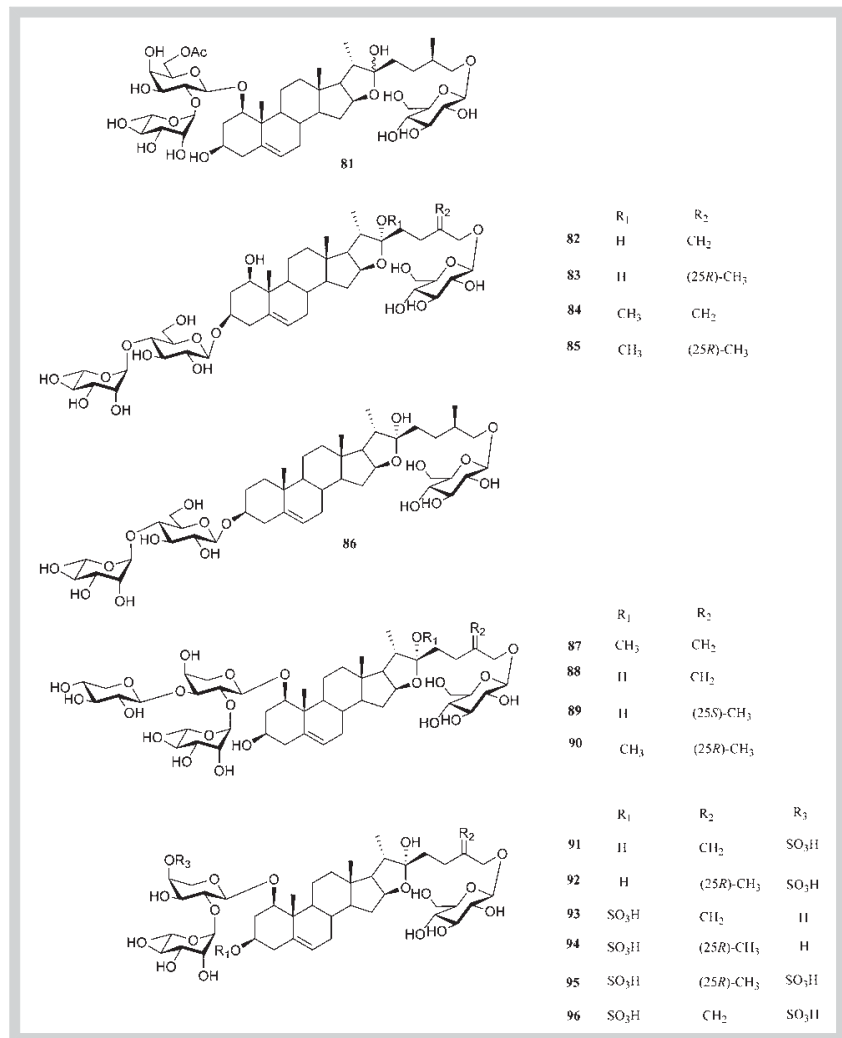

Fig. 8 Furostanol saponins (81) isolated from R. colchicus and $R$. hypoglossum and (82-96) from $R$. colchicus.

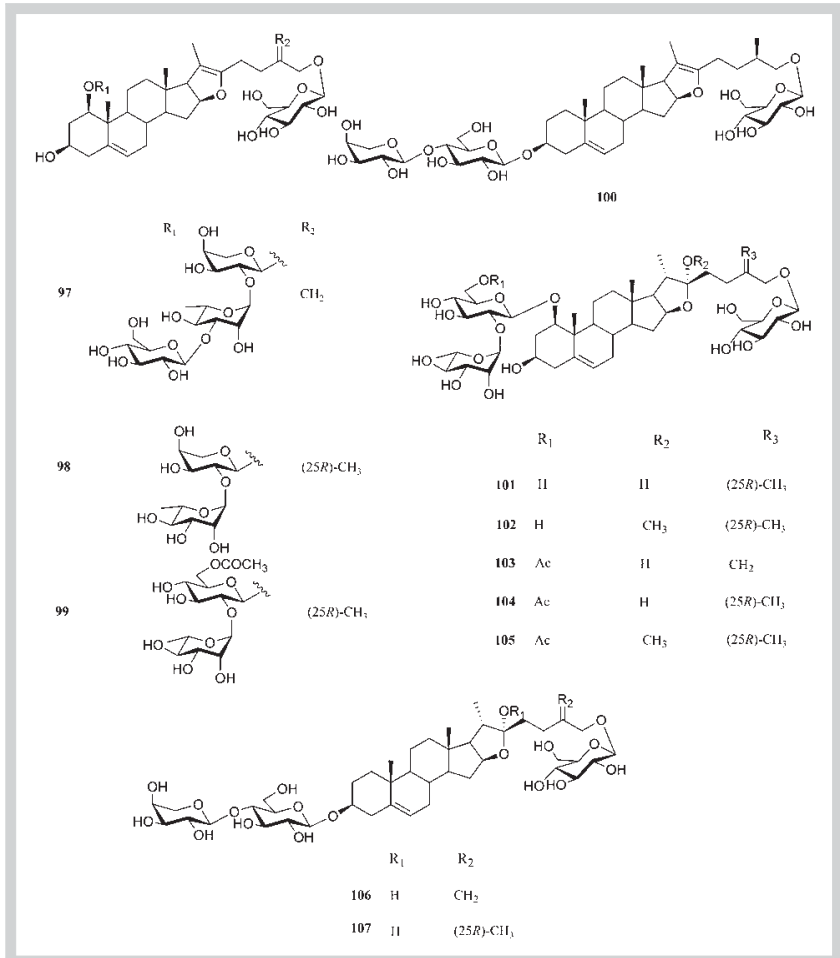

Fig. 9 Furostanol saponins (97-107) isolated from R. ponticus.

These results suggested a differential distribution of $\alpha$ adrenergic receptors on greater saphenous veins from non-varicose patients compared to those with primary varicose disease [59]. Ruscus extract was able to inhibit the activation of endothelial cells by hypoxia, a condition that mimics venous blood stasis. This effect was shown by the decrease in ATP content and the activation of phospholipase A2 as well as the subsequent increase in neutrophil adherence, probably explaining some of the beneficial therapeutic effects of this product in the treatment of chronic venous insufficiency patients [60].

Besides studies reporting the efficacy in venous insufficiency, other studies deal with the antimicrobial activity against eight bacterial and five fungal strains, and antioxidant activity of extracts of R. aculeatus and R. hypoglossum as well as of some compounds previously isolated from them ( $p$-coumaric, caffeic acids, and rutin). Investigated extracts and isolated compounds showed antibacterial and, especially, antifungal activity. In some cases, this activity was better than standard drugs (streptomycin, ampicillin, bifonazole, ketoconazole) [16]. The in vivo anti-inflammatory effect of the crude steroidal saponin mixture extracted from the rhizomes of $R$. aculeatus was investigated in graded doses $(125 \mathrm{mg} / \mathrm{kg}, 250 \mathrm{mg} / \mathrm{kg}$, and $500 \mathrm{mg} / \mathrm{kg}$ ) using two rat models of acute inflammation. The results of the experiment showed a dose-dependent anti-inflammatory effect of the crude steroidal saponin mixture. The anti-inflammatory effect could be superior to the reference drug diclofenac $(20 \mathrm{mg} / \mathrm{kg}$ ) according to the dose and moment of determination. At least one of the anti-inflammatory mechanism of action of the crude steroidal saponin mixture is the inhibition of prostaglandin activity, as for diclofenac [7]. Ruscogenin has been found to exert significant anti-inflammatory and anti-thrombotic activities. A study was carried out to investigate the mechanism involved in the inhibition of endothelial responses to cytokines during inflammatory and vascular disorders exerted by ruscogenin. It inhibited adhesion of leukocytes to a human umbilical vein endothelial cell line (ECV304) injured by TNF- $\alpha$ in a concentration-dependent manner. The results showed that ruscogenin significantly suppressed zymosan Aevoked peritoneal total leukocyte migration in mice in a dose-dependent manner, while it had no obvious effect on celiac prostaglandin E2 (PGE2) content in peritoneal exudant. Ruscogenin also inhibited TNF- $\alpha$-induced overexpression of intercellular adhesion molecule-1 (ICAM-1) both at the mRNA and protein levels, and suppressed nuclear factor- $k \mathrm{~B}$ (NF- $k \mathrm{~B}$ ) activation considerably by decreasing NF- $k$ B p 65 translocation and DNA binding activity [11].

The comparison of anti-inflammatory activities of ruscogenin and its succinylated derivative, RUS-2HS, was performed. Both compounds reduced TNF- $\alpha$-induced adhesion of human promyelocytic leukemia cells (HL-60) to endothelial ECV304 cells with $\mathrm{IC}_{50}$ values of $6.90 \mathrm{nM}$ and $7.45 \mathrm{nM}$, respectively. They also inhibited the overexpression of ICAM-1 in ECV304 cells at the mRNA level as evaluated by real-time PCR and at the protein level evaluated by flow cytometry with a similar potency. Such data demonstrate that the functional groups of ruscogenin were not blocked by derivatization [61]. Most in vitro and in vivo experiments with $R$. aculeatus were performed with its extracts and steroidal aglycones and not with the pure saponins [62]. The activity on the thrombin-induced hyperpermeability of human microvascular endothelial cells (HMEC-1) of saponins isolated from R. aculeatus was investigated in vitro. Some saponins were able to reduce the thrombin-induced hyperpermeability of endothelial cells with results comparable to those of the aglycone neoruscogenin. The latter compound showed a slight but concentration- 


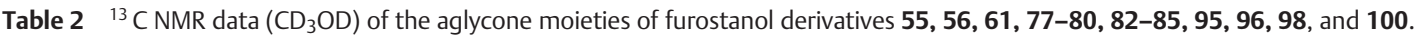

\begin{tabular}{|c|c|c|c|c|c|c|c|c|c|c|c|c|c|c|c|}
\hline & $\begin{array}{c}55 \\
{[40]}\end{array}$ & $\begin{array}{r}56 \\
{[40]}\end{array}$ & $\begin{array}{c}61 \\
{[39]}\end{array}$ & $\begin{array}{c}77 \\
{[40]}\end{array}$ & $\begin{array}{r}78 \\
{[40]}\end{array}$ & $\begin{array}{r}79 \\
{[40]}\end{array}$ & $\begin{array}{r}80 \\
{[81]}\end{array}$ & $\begin{array}{c}82 \\
{[17]}\end{array}$ & $\begin{array}{r}83 \\
{[17]}\end{array}$ & $\begin{array}{r}84 \\
{[17]}\end{array}$ & $\begin{array}{r}85 \\
{[17]}\end{array}$ & $\begin{array}{r}95 \\
{[17]}\end{array}$ & $\begin{array}{r}96 \\
{[17]}\end{array}$ & $\begin{array}{l}98 \\
{[6]}\end{array}$ & $\begin{array}{r}100 \\
{[6]}\end{array}$ \\
\hline 1 & 83.9 & 83.7 & 84.2 & 85.5 & 85.4 & 85.6 & 83.5 & 78.8 & 78.9 & 78.8 & 78.8 & 83.8 & 83.9 & 84.1 & 38.3 \\
\hline 2 & 36.8 & 37.0 & 37.2 & 38.8 & 38.7 & 38.8 & 37.4 & 40.4 & 40.4 & 40.3 & 40.2 & 34.4 & 34.4 & 37.3 & 30.5 \\
\hline 3 & 68.6 & 69.0 & 68.9 & 68.6 & 68.6 & 68.7 & 68.2 & 75.9 & 75.8 & 76.0 & 75.7 & 75.9 & 75.9 & 69.0 & 79.7 \\
\hline 4 & 43.0 & 43.2 & 43.2 & 43.2 & 43.2 & 43.0 & 43.9 & 39.7 & 39.9 & 39.8 & 39.7 & 40.6 & 40.5 & 43.2 & 39.6 \\
\hline 5 & 139.2 & 139.2 & 139.3 & 138.7 & 139.0 & 138.8 & 139.6 & 139.0 & 138.7 & 139.0 & 138.8 & 139.0 & 138.9 & 139.4 & 142.1 \\
\hline 6 & 125.4 & 125.6 & 125.5 & 126.5 & 126.4 & 126.5 & 124.7 & 126.0 & 126.2 & 126.1 & 126.0 & 126.5 & 126.5 & 125.7 & 122.5 \\
\hline 7 & 32.2 & 32.6 & 32.5 & 32.8 & 33.0 & 32.6 & 32.1 & 32.6 & 32.7 & 32.5 & 32.6 & 32.5 & 32.5 & 32.6 & 32.9 \\
\hline 8 & 33.6 & 33.8 & 33.9 & 33.8 & 33.8 & 33.8 & 32.9 & 33.6 & 33.6 & 33.6 & 33.7 & 33.4 & 33.5 & 33.8 & 32.5 \\
\hline 9 & 50.9 & 51.1 & 51.0 & 50.6 & 50.7 & 50.7 & 50.4 & 52.0 & 51.8 & 51.2 & 51.7 & 51.0 & 51.1 & 51.2 & 51.6 \\
\hline 10 & 43.5 & 43.4 & 43.0 & 43.7 & 43.6 & 43.7 & 43.1 & 43.7 & 43.6 & 43.7 & 43.8 & 43.2 & 43.1 & 43.3 & 38.0 \\
\hline 11 & 24.7 & 25.0 & 24.9 & 24.0 & 24.0 & 24.0 & 24.2 & 24.3 & 24.5 & 24.2 & 24.6 & 24.0 & 24.1 & 24.6 & 21.8 \\
\hline 12 & 40.7 & 41.1 & 41.0 & 40.8 & 40.9 & 40.9 & 40.2 & 40.7 & 40.9 & 40.8 & 41.0 & 40.9 & 40.9 & 41.0 & 40.7 \\
\hline 13 & 41.6 & 41.4 & 40.8 & 41.2 & 41.4 & 41.4 & 42.9 & 41.0 & 41.2 & 41.0 & 41.3 & 41.0 & 41.0 & 44.1 & 43.4 \\
\hline 14 & 57.2 & 57.5 & 57.6 & 57.4 & 57.5 & 57.5 & 55.1 & 57.8 & 57.6 & 57.9 & 57.7 & 57.8 & 57.7 & 56.2 & 56.2 \\
\hline 15 & 32.5 & 32.6 & 32.6 & 32.7 & 32.6 & 32.7 & 34.7 & 32.8 & 32.8 & 32.7 & 32.8 & 32.6 & 32.5 & 34.9 & 34.9 \\
\hline 16 & 81.8 & 82.4 & 82.4 & 81.8 & 82.2 & 82.0 & 84.5 & 82.3 & 82.4 & 82.1 & 82.3 & 82.3 & 82.3 & 85.2 & 85.2 \\
\hline 17 & 63.7 & 65.0 & 64.9 & 64.0 & 64.1 & 64.1 & 64.6 & 65.2 & 65.3 & 65.2 & 65.3 & 64.8 & 65.1 & 65.5 & 65.5 \\
\hline 18 & 16.7 & 17.1 & 16.6 & 16.8 & 16.9 & 16.9 & 14.5 & 16.6 & 16.8 & 16.5 & 16.7 & 16.7 & 16.7 & 14.6 & 14.6 \\
\hline 19 & 14.9 & 15.1 & 14.7 & 14.5 & 14.5 & 14.6 & 15.1 & 13.3 & 13.2 & 13.4 & 13.2 & 14.7 & 14.7 & 15.1 & 19.6 \\
\hline 20 & 40.4 & 41.0 & 40.9 & 40.8 & 40.9 & 41.1 & 104.2 & 40.8 & 41.0 & 40.8 & 41.0 & 41.0 & 41.0 & 105.5 & 105.3 \\
\hline 21 & 15.4 & 15.9 & 15.7 & 15.8 & 16.0 & 16.1 & 11.8 & 15.8 & 15.7 & 15.7 & 15.8 & 16.3 & 15.8 & 11.5 & 11.6 \\
\hline 22 & 111.7 & 113.3 & 113.9 & 111.1 & 113.7 & 111.3 & 151.5 & 113.3 & 113.2 & 113.0 & 113.2 & 113.3 & 113.3 & 152.7 & 152.7 \\
\hline 23 & 37.4 & 32.1 & 31.3 & 37.5 & 37.3 & 31.4 & 31.1 & 32.0 & 31.1 & 32.1 & 31.1 & 31.1 & 32.5 & 24.0 & 23.8 \\
\hline 24 & 28.3 & 28.5 & 28.9 & 28.5 & 28.4 & 28.6 & 24.7 & 24.8 & 28.8 & 28.4 & 28.7 & 28.8 & 28.4 & 31.3 & 31.1 \\
\hline 25 & 147.4 & 147.1 & 34.7 & 147.0 & 147.3 & 34.8 & 146.3 & 146.5 & 34.8 & 146.6 & 34.7 & 34.8 & 146.8 & 34.1 & 34.1 \\
\hline 26 & 72.4 & 72.4 & 75.9 & 72.6 & 72.4 & 75.6 & 71.7 & 72.5 & 75.2 & 72.4 & 75.3 & 75.2 & 72.4 & 75.7 & 75.7 \\
\hline 27 & 112.1 & 112.2 & 16.9 & 111.9 & 111.9 & 17.1 & 11.6 & 112.0 & 17.0 & 112.1 & 17.1 & 17.0 & 112.0 & 17.1 & 17.1 \\
\hline
\end{tabular}

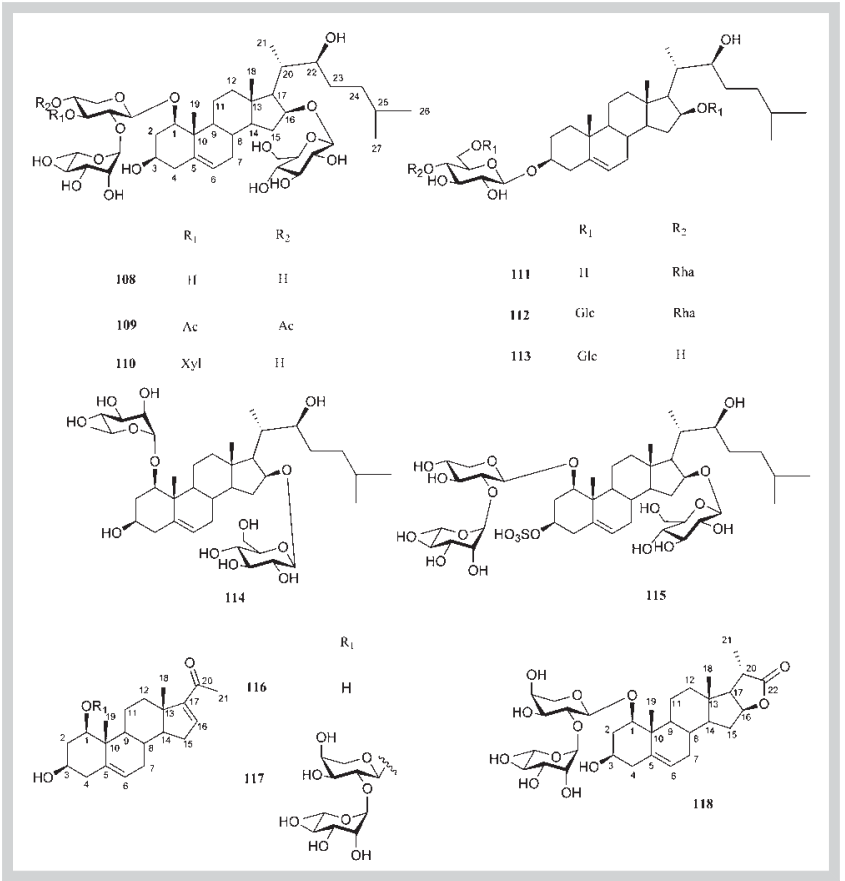

Fig. 10 Cholestane (108-115) and pregnane (116-118) saponins isolated from Ruscus spp.

dependent reduction in hyperpermeability to $71.8 \%$ at $100 \mu \mathrm{M}$ [62].
Studies dealing with the pharmacological properties of $R$. aculeatus extracts showed that compounds exhibiting these properties were the steroidal glycosides ruscin and ruscoside and their hydrolysis products desglucoruscin, desglucodesrhamnoruscin, and desglucoruscoside. The pharmacological activity seems to increase with the decrease of the number of the sugar residues [63]. For these reasons, a number of methods for enzymatic or chemical hydrolysis of $R$. aculeatus have been developed. A bioconversion process to produce the monoglycoside desglucodesrhamnoruscin from dry extracts of the rhizome of $R$. aculeatus has been developed using enzyme preparations containing a $\beta$-glucopyranosidase and an $\alpha$-rhamnopyranosidase [63].

Furthermore, aculeoside A exhibited inhibitory activity on cell growth of leukemia HL-60 cells with an $\mathrm{IC}_{50}$ value of $0.48 \mu \mathrm{g}$. $\mathrm{mL}^{-1}$, while aculeoside B was inactive [31]. Also compounds $\mathbf{4 , 5}$, 9-11, 22-28, and 63-75 were tested for their cytotoxic activity against HL-60 cells. Among the tested compounds, 10, 25, 68 and 73 showed an $\mathrm{IC}_{50}$ ranging from $3.0 \mu \mathrm{M}$ to $3.7 \mu \mathrm{M}[27,33]$.

\section{Formulations Containing Ruscus aculeatus Extracts}

A number of products based on $R$. aculeatus acting on the venous system have been developed over the last 50 years. Recent studies have also demonstrated the efficacy of a combination of Rusci rhizome with hesperidin methylchalcone and ascorbic acid against vascular disease $[64,65]$. Indeed, some products have proven to be highly successful, such as Cyclo 3 Fort (Fabroven) and Phlebodril [66].

In particular, Cyclo 3 Fort is a formulation of the root extract of $R$. aculeatus (150 mg per capsule), hesperidin methyl chalcone 


\begin{tabular}{|c|c|c|c|c|c|}
\hline & $109^{\mathrm{a}}[22]$ & $111^{a}[22]$ & $112^{\mathrm{a}}[22]$ & $115^{\mathrm{a}}[17]$ & $118^{\mathrm{c}}[6]$ \\
\hline 1 & 84.1 & 37.4 & 37.3 & 84.3 & 84.3 \\
\hline 2 & 37.0 & 30.1 & 30.1 & 34.6 & 37.1 \\
\hline 3 & 67.9 & 78.2 & 78.2 & 76.0 & 68.8 \\
\hline 4 & 43.5 & 39.2 & 39.2 & 40.7 & 43.2 \\
\hline 5 & 138.9 & 140.9 & 140.7 & 138.7 & 139.4 \\
\hline 6 & 125.0 & 121.8 & 121.9 & 127.2 & 125.3 \\
\hline 7 & 31.6 & 32.1 & 32.0 & 32.5 & 32.4 \\
\hline 8 & 33.1 & 31.8 & 31.6 & 34.0 & 33.8 \\
\hline 9 & 50.2 & 50.4 & 50.3 & 51.3 & 51.2 \\
\hline 10 & 42.6 & 36.9 & 36.9 & 43.0 & 43.2 \\
\hline 11 & 24.0 & 21.0 & 21.0 & 24.6 & 24.0 \\
\hline 12 & 40.5 & 40.3 & 39.9 & 41.5 & 39.1 \\
\hline 13 & 42.0 & 42.9 & 42.3 & 42.8 & 41.9 \\
\hline 14 & 51.1 & 54.7 & 55.0 & 56.4 & 55.7 \\
\hline 15 & 37.1 & 37.6 & 36.8 & 37.8 & 34.0 \\
\hline 16 & 82.5 & 71.3 & 82.5 & 83.2 & 84.5 \\
\hline 17 & 57.9 & 59.6 & 57.8 & 59.1 & 60.1 \\
\hline 18 & 13.7 & 13.3 & 13.4 & 13.7 & 14.3 \\
\hline 19 & 14.8 & 19.3 & 19.3 & 14.9 & 14.9 \\
\hline 20 & 35.8 & 37.4 & 35.8 & 36.2 & 37.5 \\
\hline 21 & 12.5 & 13.4 & 12.5 & 11.8 & 17.9 \\
\hline 22 & 73.0 & 73.2 & 73.0 & 74.5 & 184.1 \\
\hline 23 & 33.6 & 29.9 & 33.7 & 33.0 & \\
\hline 24 & 36.6 & 36.4 & 36.6 & 37.0 & \\
\hline 25 & 28.8 & 28.4 & 28.8 & 29.4 & \\
\hline 26 & 22.9 & 22.6 & 22.9 & 23.3 & \\
\hline 27 & 23.0 & 23.2 & 23.0 & 23.3 & \\
\hline
\end{tabular}

Table $3{ }^{13}$ C NMR data of the aglycone moieties of cholestane derivatives 109, 111, 112, 115 , and of pregnane derivative 118.

a Pyridine- $\mathrm{d}_{5}{ }^{\mathrm{c}} \mathrm{CD}_{3} \mathrm{OD}$

(150 mg), and ascorbic acid (100 mg) used to increase the venous tone in patients with venous disease. Studies of the effects of oral Cyclo 3 Fort on capillary permeability were carried out in hamsters with moderate diabetes and compared with hamsters treated with a placebo, showing that oral administration of Cyclo 3 Fort inhibited histamine-induced plasma exudation in hamsters with mild diabetes without affecting the glycemia [67]. Another study on the effects of Cyclo 3 Fort in cheek pouch preparations from diabetic hamsters showed that the venoarteriolar reflex, studied by measuring the internal diameter of arterioles during venular occlusion, was reversed by treatment with Cyclo 3 Fort, 10 and $50 \mathrm{mg} / \mathrm{kg}$ [68].

Janssens showed the effect of venotropic drugs, including Cyclo 3 Fort, on the respiratory activity of isolated mitochondria and in endothelial cells. The results showed that Cyclo 3 Fort protected human endothelial cells against the hypoxia-induced decrease in ATP content. In addition, it induced a concentration-dependent increase in respiratory control ratio (RCR) of liver mitochondria preincubated with the drug for $60 \mathrm{~min}$. Cyclo 3 inhibited the carbonylcyanide m-chlorophenyl hydrazone (mCCP)-induced uncoupling of mitochondrial respiration. The results suggested that the protective effects on mitochondrial respiration activity by Cyclo 3 Fort may explain its protective effect on the cellular ATP content in ischemic conditions and some of its beneficial therapeutic effect in chronic vascular diseases [69].

Nonsteroidal anti-inflammatory drugs such as Cyclo 3 Fort are associated with lymphocytic colitis. The mechanisms include immunological activation or attenuated immunological defences [70].

\section{Clinical Studies \\ $\nabla$}

In a key study, Rauwald and Janssen demonstrated that steroidal glycosides from Rusci rhizoma are absorbed and can be detected in their unmodified form in human plasma after oral administration [71]. A study showed the treatment of secondary lymphedema of the upper limb with Cyclo 3 Fort or placebo according to a double-blind protocol. With Cyclo 3 Fort, the reduction in the volume of arm edema, the main assessment criteria, was $12.9 \%$ after 3 months of treatment compared with a placebo $(\mathrm{p}=$ 0.009). Decreased edema tended to be more marked in the forearm compared with the upper arm where an excess of fat deposition seemed to dominate over the excess of fluid accumulation. Cyclo 3 Fort was well tolerated with minimal adverse reaction [58].

Other clinical studies showed the efficacy and safety of Cyclo 3 Fort versus hydroxyethyl rutoside in chronic venous lymphatic insufficiency [72]. The comparative efficacy of a single daily dose of two capsules of Cyclo 3 Fort in the morning versus a repeated dose of one capsule in the morning and another at noon was evaluated [73]. Thus, a single dose of two capsules of Cyclo 3 Fort in the morning appeared as effective and as well tolerated as a twice daily dose of one capsule of Cyclo 3 Fort in the morning and at noon [73]. Formulations such as Cyclo 3 Fort have been tested in clinical trials for their action on the symptoms of chronic venous insufficiency (CVI), leg pain, and edema. The effects on venous distensibility, rheological disorders, the prevention of wall dystrophy, and action on the microcirculation were examined [66]. A meta-analysis of clinical trials of Cyclo 3 Fort in the treatment of CVI demonstrated the clinical efficacy of Cyclo 3 Fort in treating patients with CVI, for which it significantly reduced the severity of the symptoms compared to the placebo. An open-label 
clinical trial conducted in 65 women with CEAP class $\mathrm{C} 2 \mathrm{~s}$ to $\mathrm{C} 3 \mathrm{~s}$ showed that the improvement in subjective functional signs under treatment with Cyclo 3 Fort was correlated with objective plethysmographic parameter improvement.

As its efficacy has been demonstrated in several clinical studies, the ESCOP (European Scientific Cooperative on Phytotherapy) recommends a daily intake of Rusci rhizoma corresponding to a dose of 7-11 mg of ruscogenins (ESCOP, 2003) [65].

\section{Analytical Techniques for the Quality Control of Ruscus aculeatus Extracts}

Frequently, medicinal herbs are commercialized as food supplements. Safety, quality, and composition assessments of food supplements based on botanical ingredients are of major concern, as they have usually not been checked through a rigorous testing process as required for the approval of therapeutic phytopreparations [74]. The variability in the content and concentrations of constituents of plant material, together with the range of extraction techniques and processing steps used by different manufacturers, results in marked variability in the quality of commercially available herbal products. Thus, quality control of herbal products is needed to ensure their consistency, safety, and efficacy [75]. $R$. aculeatus appears in a great number of dietary supplement patents [39], and several preparations are on the market as food supplements. As cited above, the mixture of the two spirostane aglycones, neoruscogenin and ruscogenin, is considered the active ingredient of $R$. aculeatus commercial drugs [19].

Several methods based on the properties of saponins, such as hemolytic and surface activity, have been used in the past for the quantitative determination of saponins in Ruscus extracts. These methods have been replaced by TLC, using a number of visualization reagents, and, more recently, by HPLC [18]. Detection of ruscogenin in 5 Ruscus taxa in Turkey by ultra-performance liquid chromatography (UPLC) was performed [13].

The detection of steroidal glycosides using UV is well known for its insensitivity because of the absence of chromophoric groups. Thereby, liquid chromatography coupled to mass spectrometry (HPLC-ESIMS) methods may work well for the identification and quantification of the steroidal saponins. HPLC-ESIMS is one of the most powerful techniques in phytochemical analysis because of its high sensitivity and specificity. HPLC-ESIMS provides structural information by analyzing the fragmentation patterns produced in HPLC-ESI/MS ${ }^{n}$ experiments.

de Combarieu et al. developed an HPLC-UV method for the analysis of saponins in R. aculeatus, and, moreover, the saponins were identified by HPLC-ESI-MS by TurbolonSpray on a single quadrupole mass spectrometer [19].

An HPLC-ESIMS analytical method based on the positive ionization mode by atmospheric pressure chemical ionization (APCI) on an ion trap instrument operating in the MSMS scan mode was developed [76]. Kite et al. observed that the use of methanol as the mobile phase under acidic conditions determined furostanol saponins hydroxylated at C-22 to chromatograph as broad peaks, while the use of methanol as mobile phases without the addition of acid determined the elution of furostanol saponins with a good peak shape, but each C-22 hydroxylated furostanol saponin was accompanied by a second chromatographic peak identified as its C-22 methyl ether. The C-22 methyl ether of deglucoruscoside was found to convert to deglucoruscoside during chromatography in acidified aqueous acetonitrile, or by dissolv- ing in water. An LC/MS/MS method was developed for the quantification of ruscogenin and neoruscogenin in hydrolyzed extracts of $R$. aculeatus. The detection was performed in the multiple reaction monitoring mode using an ion trap mass spectrometer with an electrospray ionization source operating in the positive ionization mode [77].

A study of Ruscoven gocce (drops), a preparation of Hamamelis virginiana and Vitis vinifera (hydroalcoholic leaf extract), $R$. aculeatus (freeze-dried root extract), Centella asiatica (freezedried leaf extract), and Ginkgo biloba (freeze-dried leaf extract) used to improve functionality of blood microcircles, has been carried out by electrospray mass spectrometry analysis, suggesting that either ESI(+) or ESI(-) spectra, coupled to a multivariate analysis, leads to a satisfactory and quick characterization of complex mixtures of herbal-based products [78].

More recently, to allow a rapid analysis of $R$. aculeatus species utilized as ingredients of food supplements, as well as to identify and guide the isolation of target saponins, a study of the saponin profile of $R$. aculeatus rhizomes was carried out by employing an analytical method based on high-performance liquid chromatography coupled to electrospray positive ionization tandem ion trap mass spectrometry (HPL-ESI/ITMS ${ }^{2}$ ), so improving the reported HPLC-ESIMS methods available [39]. In this study, a semipreparative reversed-phase HPLC-UV approach, resulting in being able to achieve a good chromatographic separation for Ruscus saponins, was also proposed as an alternative and suitable analytical method for the purification of Ruscus steroidal saponins.

An efficient multi-targeted method based on liquid chromatography coupled with a hybrid triple quadrupole linear ion trap analyzer was developed to screen selected botanicals, among which $R$. aculeatus was characterized by means of its appropriate biomarker ruscin [74].

\section{Conclusion}

$\nabla$

$R$. aculeatus (butcher's broom) represents the best-known and appreciated Ruscus species. Since the Middle Ages, the young shoots of $R$. aculeatus were used as medicinal agents for disorders involving the venous system, anticipating the proven success of its hydroalcoholic extract in Europe. Steroidal saponins represent the main class of chemical compounds isolated from rhizomes and roots of $R$. aculeatus and are considered to be the active compounds of $R$. aculeatus commercial products, in particular, a mixture of two spirostane aglycones, neoruscogenin and ruscogenin. A chemical investigation revealed the presence of steroidal saponins also in other Ruscus spp. Nevertheless, the scientific production focused mostly on $R$. aculeatus. A biological evaluation of $R$. aculeatus extracts were mainly focused on investigating and exploring deeper its use for venous diseases. Besides these investigations, a few other reports on the biological activity of $R$. aculeatus extracts or pure isolated compounds have been carried out so far.

Due to its benefits demonstrated in several clinical studies, oral supplementation with $R$. aculeatus is recommended. So, $R$. aculeatus appears in several commercial herbal products.

Thanks to the innovation in analytical technology, identification, and detection of chemical markers in $R$. aculeatus extracts, food supplements have been strongly improved. In particular, hyphenated techniques based on HPLC coupled to MS analysis have proved to be the most suitable for the rapid identification of com- 
pounds in the plant matrix. Moreover, taking into account that not only the main compounds but also the low-concentration compounds can affect the sample quality, fingerprint analysis might be a simple and rapid way for the identification and quality control of $R$. aculeatus commercial preparations.

\section{Conflict of Interest}

$\nabla$

The authors declare no conflict of interest.

\section{References}

$1 \mathrm{Kim} J \mathrm{H}$, Kim DK, Forest F, Fay MF, Chase MW. Molecular phylogenetics of Ruscaceae sensu lato and related families (Asparagales) based on plastid and nuclear DNA sequences. Ann Bot 2010; 106: 775-790

2 Thomas PA, Mukassabi TA. Biological Flora of the British Isles: Ruscus aculeatus. J Ecol 2014; 102: 1083-1100

3 Davis PH. Ruscus L. In: Davis PH, editor. Flora of Turkey and The East Aegean Islands. Vol. 8. Edinburgh: Edinburgh University Press; 1984: 72-74

4 Veronese G. A study on the genus Ruscus and its horticultural value. Avaible at http://wwwslidesharenet/GiulioVeronese/a-study-on-thegenus-ruscus-and-its-horticultural-value. Accessed May 5, 2016

5 Pignatti S. Flora d'Italia. Italia: Edagricole-New Business Media; 2002

6 Napolitano A, Muzashvili T, Perrone A, Pizza C, Kemertelidze E, Piacente S. Steroidal glycosides from Ruscus ponticus. Phytochemistry 2011; 72: 651-661

7 Balica G, Vostinaru O, Tamas M, Crisan G, Mogosan C. Anti-inflammatory effect of the crude steroidal saponin from the rhizomes of Ruscus aculeatus L. (Ruscaceae) in two rat models of acute inflammation. J Food Agric Environ 2013; 11: 106-108

8 Bouskela E, Cyrino FZ, Marcelon G. Effects of Ruscus extract on the internal diameter of arterioles and venules of the hamster cheek pouch microcirculation. J Cardiovasc Pharmacol 1993; 22: 221-224

9 Bouskela E, Cyrino FZ, Marcelon G. Inhibitory effect of the Ruscus extract and of the flavonoid hesperidine methylchalcone on increased microvascular permeability induced by various agents in the hamster cheek pouch. J Cardiovasc Pharmacol 1993; 22: 225-230

10 Bouskela E, Cyrino FZ, Marcelon G. Possible mechanisms for the inhibitory effect of Ruscus extract on increased microvascular permeability induced by histamine in hamster cheek pouch. J Cardiovasc Pharmacol 1994; 24: 281-285

11 Huang YL, Kou JP, Ma L, Song JX, Yu BY. Possible mechanism of the antiinflammatory activity of ruscogenin: role of intercellular adhesion molecule-1 and nuclear factor-kB. J Pharmacol Sci 2008; 108: 198-205

12 Longo L, Vasapollo G. Determination of anthocyanins in Ruscus aculeatus L. berries. J Agric Food Chem 2005; 53: 475-479

13 Guvenc A, Satir E, Coskun M. Determination of ruscogenin in Turkish Ruscus L. species by UPLC. Chromatographia 2007; 66: S141-S145

14 Ali-Shtayeh MS, Yaghmour RM, Faidi YR, Salem K, Al-Nuri MA. Antimicrobial activity of 20 plants used in folkloric medicine in the Palestinian area. J Ethnopharmacol 1998; 60: 265-271

15 Guarrera PM. Traditional phytotherapy in Central Italy (Marche, Abruzzo, and Latium). Fitoterapia 2005; 76: 1-25

16 Hadzifejzovic N, Kukic-Markovic J, Petrovic S, Sokovic M, Glamoclija J, Stojkovic D, Nahrstedt A. Bioactivity of the extracts and compounds of Ruscus aculeatus L. and Ruscus hypoglossum L. Ind Crops Prod 2013; 49: 407-411

17 Perrone A, Muzashvili T, Napolitano A, Skhirtladze A, Kemertelidze E, Piz$z a$ C, Piacente S. Steroidal glycosides from the leaves of Ruscus colchicus: isolation and structural elucidation based on a preliminary liquid chromatography-electrospray ionization tandem mass spectrometry profiling. Phytochemistry 2009; 70: 2078-2088

18 Dehghan $H$, Sarrafi $Y$, Salehi P. Antioxidant and antidiabetic activities of 11 herbal plants from Hyrcania region, Iran. J Food Drug Anal 2016; 24: $179-188$

19 de Combarieu E, Falzoni M, Fuzzati N, Gattesco F, Giori A, Lovati M, Pace $R$. Identification of Ruscus steroidal saponins by HPLC-MS analysis. Fitoterapia 2002; 73: 583-596

20 Sannie C, Lapin H. Sterolic sapogenins. VII. Neoruscogenin (3ß,1-dihydroxy-22ß,25L-5-spirostene), a new sapogenin from Ruscus aculeatus. Bull Soc Chim Fr 1957; 10: 1237-1241
21 Mimaki Y, Kuroda M, Obata Y, Sashida Y. Steroidal glycosides from the rhizomes of Ruscus hypoglossum. Nat Med 1999; 53: 266-270

22 Mimaki Y, Aoki T, Jitsuno M, Kilic CS, Coskun M. Steroidal glycosides from the rhizomes of Ruscus hypophyllum. Phytochemistry 2008; 69: 729-737

23 Mimaki Y, Aoki T, Jitsuno M, Yokosuka A, Kilic CS, Coskun M. Steroidal saponins from the rhizomes of Ruscus hypophyllum. Nat Prod Commun 2008; 3: 1671-1678

24 Panova D, Nikolov S. Steroid saponins from Ruscus hypoglossum L. Farmatsiya (Sofia) 1977; 27: 8-14

25 Mimaki Y, Kuroda M, Yokosuka A, Sashida Y. A spirostanol saponin from the underground parts of Ruscus aculeatus. Phytochemistry 1999; 51: 689-692

26 Bombardelli E, Bonati A, Gabetta B, Mustich G. Glycosides from rhizomes of Ruscus aculeatus. Fitoterapia 1971; 42: 127-136

27 Mimaki Y, Kuroda M, Kameyama A, Yokosuka A, Sashida Y. New steroidal constituents of the underground parts of Ruscus aculeatus and their cytostatic activity on HL-60 cells. Chem Pharm Bull (Tokyo) 1998; 46: 298-303

28 Barbic M, Schmidt TJ, Juergenliemk G. Novel phenyl-1-benzoxepinols from butcher's broom (Rusci rhizoma). Chem Biodivers 2012; 9: 1077-1083

29 Mimaki Y, Kuroda M, Yokosuka A, Sasahida Y. Two new bisdesmosidic steroidal saponins from the underground parts of Ruscus aculeatus. Chem Pharm Bull 1998; 46: 879-881

30 Horikawa T, Mimaki Y, Kameyama A, Sashida Y, Nikaido T, Ohmoto T. Aculeoside A, a novel steroidal saponin containing a deoxyaldoketose from Ruscus aculeatus. Chem Lett 1994: 2303-2306

31 Mimaki Y, Kuroda M, Kameyama A, Yokosuka A, Sashida Y. Aculeoside B, a new bisdesmosidic spirostanol saponin from the underground parts of Ruscus aculeatus. J Nat Prod 1998; 61: 1279-1282

32 Kameyama A, Shibuya Y, Kusuoku H, Nishizawa Y, Nakano S, Tatsuta K. Isolation and structural determination of spilacleosides $A$ and $B$ having a novel 1, 3-dioxolan-4-one ring. Tetrahedron Lett 2003; 44: 27372739

33 Mimaki Y, Kuroda M, Kameyama A, Yokosuka A, Sashida Y. Steroidal saponins from the underground parts of Ruscus aculeatus and their cytostatic activity on HL-60 cells. Phytochemistry 1998; 48: 485-493

34 Oulad-Ali A, Guillaume D, Belle R, David B, Anton R. Sulfated steroidal derivatives from Ruscus aculeatus. Phytochemistry 1996; 42: 895-897

35 Hilal SH, El-Alfy TS, Ibrahim EY. A study of the saponin content of the cladophylls of Ruscus hypoglossum L. Bull Fac Pharm 1982; 19: 85-92

36 Panova D, Nikolov S, Ahond A, Longevialle P, Poupat C. Steroidal trihydroxysapogenins from Ruscus hypoglossum. Izd. BAN; 1978: 339-343

37 Pkheidze TA, Kereselidze EV, Kemertelidze EP. Diosgenin, neoruscogenin, and ruscogenin from Ruscus ponticus, Ruscus hypophyllum, and Allium albidum. Khim Prir Soedin 1971; 7: 841-842

38 Korkashvili TS, Dzhikiya OD, Vugalter MM, Pkheidze TA, Kemertelidze EP. Steroid glycosides of Ruscus ponticus. Soobshch Akad Nauk Gruz Ssr 1985; 120: 561-564

39 Mari A, Napolitano A, Perrone A, Pizza C, Piacente S. An analytical approach to profile steroidal saponins in food supplements: The case of Ruscus aculeatus. Food Chem 2012; 134: 461-468

40 De Marino S, Festa C, Zollo F, Iorizzi M. Novel steroidal components from the underground parts of Ruscus aculeatus L. Molecules 2012; 17 : 14002-14014

41 Challinor VL, Piacente S, De Voss JJ. NMR assignment of the absolute configuration of C-25 in furostanol steroidal saponins. Steroids 2012; 77: 602-608

42 Agrawal PK, Bunsawansong P, Morris GA. NMR spectral investigations. Part 46. Dependence of the ${ }^{1} \mathrm{H}$ NMR chemical shifts of ring $\mathrm{F}$ resonances on the orientation of the 27-methyl group of spirostane-type steroidal sapogenins. Phytochemistry 1997; 47: 255-257

43 Agrawal PK, Bunsawansong P, Morris GA. Dependence of the ${ }^{1} \mathrm{H}$ NMR chemical shifts of ring $\mathrm{F}$ resonances on the orientation of the 27-meth$\mathrm{yl}$ group of spirostane-type steroidal sapogenins. Phytochemistry 1998; 47: 255-257

44 Agrawal PK. 25R/25 S stereochemistry of spirostane-type steroidal sapogenins and steroidal saponins via chemical shift of geminal protons of ring-F. Magn Reson Chem 2003; 41: 965-968

45 Jones RN, Katzenellenbogen E, Dobriner K. Steroid metabolism. XVII. The infrared absorption spectra of the steroid sapogenins. J Am Chem Soc 1953; 75: 158-166

46 Silva BP, Bernardo RR, Parente JP. New furostanol glycosides from Costus spicatus. Fitoterapia 1998; 69: 528-532 
47 Da Silva BP, De Sousa AC, Silva GM, Mendes TP, Parente JP. A new bioactive steroidal saponin from Agave attenuata. Z Naturforsch C 2002; 57 : 423-428

48 Agrawal PK. NMR spectral investigations, part 51. Dependence of ${ }^{1} \mathrm{H}$ NMR chemical shifts of geminal protons of glycosyloxy methylene $\left(\mathrm{H}_{2}-26\right)$ on the orientation of the 27-methyl group of furostane-type steroidal saponins. Magn Reson Chem 2004; 42: 990-993

49 Agrawal PK. Assigning stereo-diversity of the 27-Me group of furostane-type steroidal saponins via NMR chemical shifts. Steroids 2005; 70: $715-724$

50 Inoue K, Shimomura K, Kobayashi S, Sankawa U, Ebizuka Y. Conversion of furostanol glycoside to spirostanol glycoside by $\beta$-glucosidase in Costus speciosus. Phytochemistry 1996; 41: 725-727

51 Bombardelli E, Bonati A, Gabetta B, Mustich G. Glycosides from rhizomes of Ruscus aculeatus. II. Fitoterapia 1972; 43: 3-10

52 Capra C. Pharmacology and toxicology of some components of Ruscus aculeatus. Fitoterapia 1972; 43: 99-113

53 Rudofsky G. Improving venous tone and capillary sealing. Effect of a combination of Ruscus extract and hesperidine methyl chalcone in healthy probands in heat stress. Fortschr Med 1989; 107: 52, 55-58

54 Marcelon G, Verbeuren TJ, Lauressergues H, Vanhoutte PM. Effect of Ruscus aculeatus on isolated canine cutaneous veins. Gen Pharmacol 1983; 14: 103-106

55 Marcelon G, Pouget G, Tisneversailles J. Alpha-Adrenergic Responsiveness on Canine Thoracic-Duct Lymph - Effect of Ruscus Aculeatus Extract. Blood Vessels 1987; 24: 291

56 Rubanyi G, Marcelon G, Vanhoutte PM. Effect of temperature on the responsiveness of cutaneous veins to the extract of Ruscus aculeatus. Gen Pharmacol 1984; 15: 431-434

57 Facino RM, Carini M, Stefani R, Aldini G, Saibene L. Anti-elastase and anti-hyaluronidase activities of saponins and sapogenins from Hedera helix, Aesculus hippocastanum, and Ruscus aculeatus: factors contributing to their efficacy in the treatment of venous insufficiency. Arch Pharm 1995; 328: 720-724

58 Cluzan RV, Alliot F, Ghabboun S, Pascot M. Treatment of secondary lymphedema of the upper limb with CYCLO 3 FORT. Lymphology 1996; 29: 29-35

59 Miller VM, Rud KS, Gloviczki P. Pharmacological assessment of adrenergic receptors in human varicose veins. Int Angiol 2000; 19: 176-183

60 Bouaziz N, Michiels C, Janssens D, Berna N, Eliaers F, Panconi E, Remacle J. Effect of Ruscus extract and hesperidin methylchalcone on hypoxia-induced activation of endothelial cells. Int Angiol 1999; 18: 306-312

61 Huang YL, Kou JP, Liu JH, Liu N, Yu BY. Comparison of anti-inflammatory activities of ruscogenin, a major steroidal sapogenin from Radix ophiopogon japonicus, and its succinylated derivative, RUS-2HS. Drug Dev Res 2008; 69: 196-202

62 Barbic M, Willer EA, Rothenhofer M, Heilmann J, Furst R, Jurgenliemk G. Spirostanol saponins and esculin from Rusci rhizoma reduce the thrombin-induced hyperpermeability of endothelial cells. Phytochemistry 2013; 90: 106-113

63 Di Lazzaro A, Morana A, Schiraldi C, Martino A, Ponzone C, De Rosa M. An enzymatic process for the production of the pharmacologically active glycoside desglucodesrhamnoruscin from Ruscus aculeatus L. J Mol Catal B Enzym 2001; 11: 307-314
64 Allaert FA, Hugue C, Cazaubon M, Renaudin JM, Clavel T, Escourrou P. Correlation between improvement in functional signs and plethysmographic parameters during venoactive treatment (Cyclo 3 Fort). Int Angiol 2011; 30: 272-277

65 Boyle P, Diehm C, Robertson C. Meta-analysis of clinical trials of Cyclo 3 Fort in the treatment of chronic venous insufficiency. Int Angiol 2003; 22: $250-262$

66 Boisseau MR. Pharmacological targets of drugs employed in chronic venous and lymphatic insufficiency. Int Angiol 2002; 21: 33-39

67 Svensjo E, Bouskela E, Cyrino FZ, Bougaret S. Antipermeability effects of Cyclo 3 Fort in hamsters with moderate diabetes. Clin Hemorheol Microcirc 1997; 17: 385-388

68 Bouskela E, Cyrino FZ, Bougaret S. Effects of Cyclo 3 Fort on microvascular reactivity and the venoarteriolar reflex in diabetic hamsters. Clin Hemorheol Microcirc 1997; 17: 351-356

69 Janssens D, Delaive E, Houbion A, Eliaers F, Remacle J, Michiels C. Effect of venotropic drugs on the respiratory activity of isolated mitochondria and in endothelial cells. Br J Pharmacol 2000; 130: 1513-1524

70 Cappelli $R$, Nicora M, Di PT. Use of extract of Ruscus aculeatus in venous disease in the lower limbs. Drugs Exp Clin Res 1988; 14: 277-283

71 Rauwald HW, Janssen B. Improved Isolation and HPLC/TLC Analyses of Major Saponins from Ruscus aculeatus. Planta Med 1988; 54: 581

72 Beltramino R, Penenory A, Buceta AM. An open-label, randomized multicenter study comparing the efficacy and safety of Cyclo 3 Fort versus hydroxyethyl rutoside in chronic venous lymphatic insufficiency. Angiology 2000; 51: 535-544

73 Boccalon H, Causse C, Yubero L. Comparative efficacy of a single daily dose of two capsules Cyclo 3 Fort in the morning versus a repeated dose of one capsule morning and noon. A one-month study. Int Angiol 1998; 17: 155-160

74 Mathon C, Duret M, Kohler M, Edder P, Bieri S, Christen P. Multi-targeted screening of botanicals in food supplements by liquid chromatography with tandem mass spectrometry. Food Chem 2013; 138: 709-717

75 Masullo M, Montoro P, Mari A, Pizza C, Piacente S. Medicinal plants in the treatment of women's disorders: Analytical strategies to assure quality, safety and efficacy. J Pharm Biomed Anal 2015; 113: 189-211

76 Kite GC, Porter EA, Simmonds MSJ. Chromatographic behaviour of steroidal saponins studied by high-performance liquid chromatographymass spectrometry. J Chromatogr A 2007; 1148: 177-183

77 Vlase L, Kiss B, Balica G, Tamas M, Crisan G, Leucuta SE. High-throughput LC/MS/MS analysis of ruscogenin and neoruscogenin in Ruscus aculeatus L. J AOAC Int 2009; 92: 1055-1059

78 Mattoli L, Cangi F, Ghiara C, Burico M, Maidecchi A, Bianchi E, Ragazzi E, Bellotto $L$, Seraglia $R$, Traldi $P$. A metabolite fingerprinting for the characterization of commercial botanical dietary supplements. Metabolomics 2011; 7: 437-445

79 Mimaki Y, Kuroda M, Ide A, Kameyama A, Yokosuka A, Sashida Y. Steroidal saponins from the aerial parts of Dracaena draco and their cytostatic activity on HL-60 cells. Phytochemistry 1999; 50: 805-813

80 Inoue K, Kobayashi S, Noguchi H, Sankawa U, Ebizuka Y. Spirostanol and furostanol glycosides of Costus speciosus (Koenig.) Sm. Nat Med 1995; 49: $336-339$

81 Mimaki Y, Takaashi Y, Kuroda M, Sashida Y, Nikaido T. Steroidal saponins from Nolina recurvata stems and their inhibitory activity on cyclic AMP phosphodiesterase. Phytochemistry 1996; 42: 1609-1615 